\title{
A Combined Healthy Lifestyle Index in Assessing the Relationship with Irritable Bowel Syndrome: Better Prediction of the Disorder
}

ISSN: 2637-7632

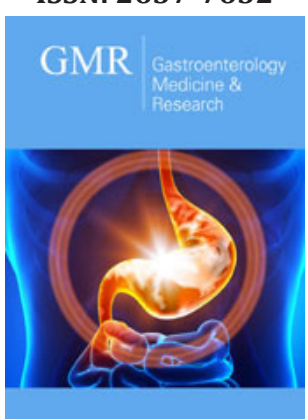

*Corresponding author: Parvane Saneei, Department of Community Nutrition, School of Nutrition and Food Science, Isfahan, Iran

Submission: 麅 May 6, 2019

Published: 恝July 18, 2019

Volume 3 - Issue 3

How to cite this article: Parvane Saneei, Ahmad Esmaillzadeh. A Combined Healthy Lifestyle Index in Assessing the Relationship with Irritable Bowe Syndrome: Better Prediction of the Disorder. Gastro Med Res. 3(3). GMR.000564. 2019.

DOI: 10.31031/GMR.2019.03.000564

Copyright@ Parvane Saneei, This article is distributed under the terms of the Creative Commons Attribution 4.0 International License, which permits unrestricted use and redistribution provided that the original author and source are credited.
Parvane Saneei* and Ahmad Esmaillzadeh

Department of Community Nutrition, Iran

\section{Opinion}

Irritable Bowel Syndrome (IBS) is one of the most common gastrointestinal disorders worldwide. Symptoms of IBS include chronic or recurrent abdominal pain or discomfort associated with abnormal bowel habit [1]. IBS was prevalent approximately in $10-15 \%$ of different population groups and was found predominantly in women [2]. Several important factors are involved in etiology of IBS including disrupted gut microbiota function, immunological dysfunction, food intolerance, altered gut motility, psychological distress factors and genetic predisposition. Several investigations have evaluated the relationship between lifestyle-related factors and IBS. Numerous modifiable risk factors, including poor dietary intakes, physical inactivity, smoking, having high level of distress and obesity, have been studied in association with the disorder; however, findings were conflicting. For example, in an internet survey of general population in Japan, positive relationships were found between physical inactivity, insufficient sleep, meals irregularly, insufficient intake of vegetable and meat and being highly susceptible to stress, as independent predictors, with IBS symptoms [3]. However, smoking -as a risk factor for IBS- was not taken into account in that study. Another survey has also documented that children with IBS were susceptible to stress and had impaired sleep and eating habits [4]. In Lebanese adults, being water pipe smoker and alcohol consumer were associated with a higher prevalence of IBS; while cigarettes smoking, and physical exercise were not significantly associated with IBS occurrence [5]. Individuals with IBS in London habitually had more intake of sodium and low intake of fiber, selenium and iodine, as well as having low scores for diet quality [6]. However, a cross-sectional study among IBS patients in the United Kingdom showed that the balance of energy macronutrients was favorable, intakes of selected micronutrients significantly exceeded the reference nutrient intakes [7]. Another investigation in Sweden found the same results in IBS patients compared with control group from a nation-wide dietary survey [8]. Most of these studies have focused on the relation of a certain behavior, rather than all lifestyle factors, and IBS; the benefits of considering multiple components of a healthy lifestyle have not studied. As shown in Figure 1, an overall healthy lifestyle index that incorporates more than one of lifestyle-related factors can be more effective in predicting the risk for IBS than any single factor.

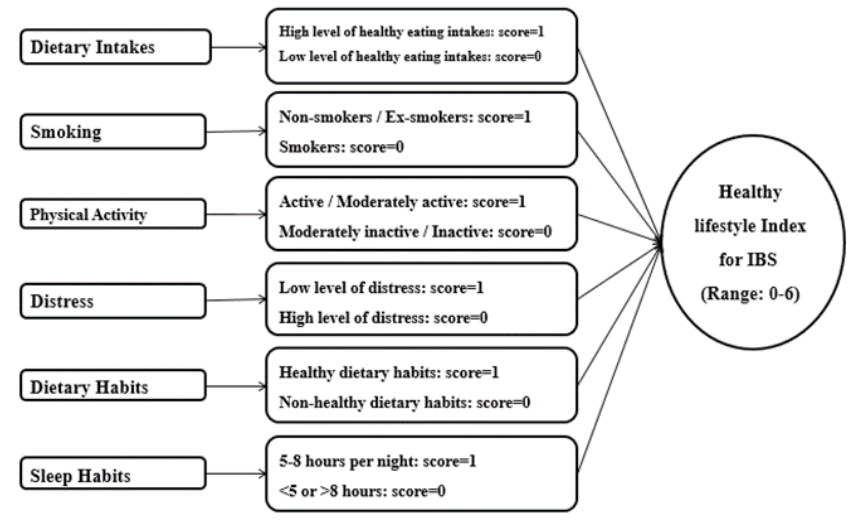

Figure 1: A flow chart for developing a healthy lifestyle index for irritable bowel syndrome. 


\section{References}

1. Chey WD, Kurlander J, Eswaran S (2015) Irritable bowel syndrome: A clinical review. JAMA 313(9): 949-958.

2. Fukudo S, Kaneko H, Akiho H, Inamori M, Endo Y, et al. (2015) Evidencebased clinical practice guidelines for irritable bowel syndrome. Gastroenterol 50(1): 11-30.

3. Miwa H (2012) Lifestyle in persons with functional gastrointestinal disorders-large-scale internet survey of lifestyle in Japan. Neurogastroenterol Motil 24(5): 464-471.

4. Kumagai H, Yokoyama K, Imagawa T, Yamagata T (2016) Functional dyspepsia and irritable bowel syndrome in teenagers: Internet survey. Pediatr Int 58(8): 714-720.
5. Chatila R, Merhi M, Hariri E, Sabbah N, Deeb ME (2017) Irritable bowel syndrome: Prevalence, risk factors in an adult Lebanese population. BMC Gastroenterol 17(1): 137.

6. Staudacher HM, Ralph FSE, Irving PM, Whelan K, Lomer MCE (2019) Nutrient Intake, diet quality, and diet diversity in irritable bowel syndrome and the impact of the low FODMAP diet. J Acad Nutr Diet S2212-2672(18): 31829-X.

7. Williams EA, Nai X, Corfe BM (2011) Dietary intakes in people with irritable bowel syndrome. BMC Gastroenterol 11: 9.

8. Böhn L, Störsrud S, Simrén M (2013) Nutrient intake in patients with irritable bowel syndrome compared with the general population. Neurogastroenterol Motil 25(1): 23-30. 